\title{
Cost-effective conservation of an endangered frog under uncertainty
}

Lucy E. Rose*, Geoffrey W. Heard, Yung En Chee, and Brendan A. Wintle

School of BioSciences, University of Melbourne, Victoria 3010, Australia

*email 1ros@student.unimelb.edu.au

Running title: Choosing cost-effective and robust options

Keywords: cost-benefit, efficiency, prioritization, risk, amphibian, Bayesian, metapopulation, population viability 


\begin{abstract}
How should managers choose among conservation options when resources are scarce and there is uncertainty regarding the effectiveness of actions? Well-developed tools exist for prioritizing areas for one-off and binary actions (e.g. protect versus not-protect), but methods for prioritizing incremental or ongoing actions (such as habitat creation and maintenance) remain uncommon. We present an approach that combines metapopulation viability and cost-effectiveness analyses to select among alternative conservation actions, while accounting for uncertainty. In our study, 'cost-effectiveness' is the ratio between the benefit of an action and its economic cost, where benefit is the change in metapopulation viability. We demonstrate the approach with a case study of the endangered growling grass frog, Litoria raniformis, which is threatened by urban development. We extended a Bayesian model to predict metapopulation viability under nine urbanization and management scenarios, and incorporated the full probability distribution of possible outcomes for each scenario into the cost-effectiveness analysis. This allowed us to discern between costeffective alternatives that were robust to uncertainty and those with a relatively high risk of failure. Our analyses suggest that creation and maintenance of wetlands dedicated to L. raniformis is the only cost-effective action likely to result in a sufficiently low risk of extinction. To our knowledge this is the first study to use Bayesian metapopulation viability analysis to explicitly incorporate parametric and demographic uncertainty into a costeffective evaluation of conservation actions. The approach offers guidance to decisionmakers aiming to achieve cost-effective conservation under uncertainty.
\end{abstract}




\section{Introduction}

Cost-effective conservation is increasingly important as the number of endangered species grows, without commensurate increases in conservation budgets. Models and decision support tools can help identify cost-effective strategies that are robust to uncertainty (Wintle et al. 2011; Addison et al. 2013). The conservation prioritization literature has been heavily focused on the binary decision problem of protect or not-protect (Watts et al. 2009;

Sebastián-González et al. 2011; Pouzols et al. 2012). However, in reality, conserving species requires action on multiple fronts, and managers need to choose from a range of one-off, incremental and ongoing actions, such as habitat creation, revegetation, control of invasive flora and fauna, and fire management (Wilson et al. 2007; Wintle et al. 2011; Smith \& Sutherland 2014). When alternative actions differ in timing, costs and expected effectiveness, prioritization can be challenging. Cost-effectiveness analysis (CEA) provides a systematic and defensible means to compare conservation options and enable better-informed decisions based on simultaneous consideration of costs and benefits (Joseph et al. 2009).

Cost-effectiveness analysis has commonly been neglected in environmental decision-making, but this is changing as conservation scientists demonstrate its relevance and advantages (Ferraro 2003; Naidoo et al. 2006). For example, Wilson et al. (2006) included costs along with biodiversity data and land conversion rates to rank five priority regions in Southeast Asia for conservation investment. Joseph et al (2009) prioritized conservation efforts for all of New Zealand's listed threatened species, and Sebastian-Gonzales et al. (2011) prioritized the most cost-effective actions for conserving 25 water-bird species in the Vega Baja Valley in southeast Spain. Key recent advances include incorporation of multiple actions and dynamic ecological processes (e.g. Joseph et al. 2009; Visconti et al. 2010; Fuentes et al. 2015; Santika et al. 2015). 
Choosing cost-effective actions requires knowledge of the benefit of conservation actions. Despite recent advances, benefits in most published applications are estimated using static models, such as species distribution models (Guisan et al. 2013) and the link to persistence is typically implicit or assumed (Cabeza \& Moilanen 2001). For example, it is often assumed that species persistence is directly proportional to the area of occupied habitat protected (e.g. Wilson et al. 2006; Wilson et al. 2007). Models of species persistence, such as population viability analyses (PVA; Burgman et al. 1993), can provide a direct measure of the benefit of conservation actions. PVA is based on a model of the population dynamics of the focal species and allows population trajectories to be simulated through time (Burgman et al. 1993). As such, it offers explicit and rigorous assessments of the potential benefits of conservation options, and allows uncertainty in those to be estimated and directly considered. PVA has been used to assess and select among management options (Akçakaya et al. 1995; Wintle et al. 2005; Southwell et al. 2008; Newbold \& Siikamäki 2009). However, few studies have incorporated PVA in cost-effectiveness analyses (but see Duca et al. 2009; Newbold \& Siikamäki 2009; Kuemmerle et al. 2011; Sebastián-González et al. 2011; Santika et al. 2015). To our knowledge, no study has explicitly addressed the influence of uncertainty in population projections on the cost-effectiveness of alternative actions or provided guidance on how to make decisions that are robust to that uncertainty. Newbold and Siikamäki (2009) and Kuemmerle et al. (2011) measure and discuss the influence of uncertainty in their predictions of population viability but it is not incorporated directly in their measures of costeffectiveness. Wintle et al. (2011) considered the robustness of climate adaptation conservation options to uncertainty about their effectiveness, though they do not explicitly utilize the uncertainty estimates provided by their population models. 
Of particular relevance to our study, Gilioli et al. (2008) used a metapopulation model to quantify benefits and prioritize conservation options for frogs, and they considered uncertainty in the predictions of interventions. However, uncertainty and costs were not incorporated in their ranking; a single type of action (wetland creation) was explored, and their metapopulation viability model included only one factor as a determinant of population persistence (wetland area).

In this study, we incorporate multiple management options, cost-effectiveness and uncertainty in an analysis of conservation options for the endangered Australian frog, Litoria raniformis. We use a Bayesian model of metapopulation viability for L. raniformis (Heard et al. 2013), which accounts for several key aspects of wetland habitat quality, and combine it with a CEA. In our approach, adoption of a Bayesian model allows parameter and demographic uncertainty to be propagated through to the calculation of the cost-effectiveness of alternative management actions. We apply the approach to a case study in which urbanization threatens the focal species, and in which managers can choose among a suite of wetland creation and enhancement options to mitigate that threat.

\section{Methods}

Case study

This study focused on a remnant metapopulation of L. raniformis in an area zoned for urbanization in the rural north of Melbourne, Victoria, Australia. The study area includes the Lockerbie Urban Growth Precinct (henceforth, the Precinct) and local catchment areas (Figure 1). Populations of L. raniformis occupy pools along streams and farm dams in the area (Heard et al. 2012b). For simplicity, we refer to both types of habitat as 'sites' or 'wetlands'. 
The Victorian Government's sub-regional strategy for L. raniformis (SRS) details conservation goals for the species across Melbourne's urban-growth zone (DEPI 2013). Linked to this is a dedicated 'Conservation management plan' (CMP) for the Precinct (Ecology Australia 2012). These documents map suitable habitat for L. raniformis, including Category $1(\mathrm{C} 1)$ habitat of high conservation significance. They also describe the regional impacts of urbanization and outline activities to mitigate these impacts. See Appendix S1 for further explanation of the SRS and CMP.

We are specifically concerned with the persistence of $L$. raniformis within the Precinct and used the CMP to define candidate conservation scenarios in our analyses. However, habitat removal and degradation processes associated with urbanization proposed in the broader study area (Fig.1) were incorporated, as these have important implications for persistence within the Precinct. The broader study area contains the 'focal metapopulation' which covers 119 sites (Fig. 1): 26 wetlands monitored for L. raniformis between the 2001/2002 and 2011/2012 active seasons (October-April; see below); 22 neighboring wetlands mapped as potential habitat by Heard and McCarthy (2012), and; 71 additional sites mapped as habitat by DEPI (2013). Average patch size was $1550 \mathrm{~m}^{2}$ and there were roughly an equal number of lentic and lotic sites. Of the 119 sites, 51 were designated as C1 habitat (Fig. 1).

In the Precinct itself there are 46 wetlands, 25 of which are listed as $\mathrm{C} 1$ habitat (Fig. 1). Proposals to mitigate the impact of urbanization of the Precinct on L. raniformis include protection of $\mathrm{C} 1$ habitat, habitat enhancement works, and creation of dedicated wetlands for the frog. Stormwater retention basins and water quality treatment wetlands (henceforth, SWM wetlands) are also proposed for the Precinct. However, they are part of statutory requirements for managing urban runoff; they are not designed for L. raniformis conservation (Victorian Stormwater Committee 1999; Ecology Australia 2012). For the purposes of this study, we treated planned SWM wetlands (Ecology Australia 2012; GAA 2012) as additional 
habitat for L. raniformis, because the species does use these wetlands in northern Melbourne (Hamer et al. 2012; Heard et al. 2012a). However, we incorporate the fact that SWM wetlands accumulate sediments and pollutants, and diminish in quality for L. raniformis through time (described below).

\section{Metapopulation model and simulations}

The existing metapopulation model for L. raniformis in this region (Heard et al. 2013) defines the rates of population persistence and colonization among wetlands dependent on their characteristics and proximity. Specifically, the logit of the probability of population persistence $(\phi)$ is modeled as a linear, additive function of wetland effective area, aquatic vegetation cover and connectivity (see Table 1), while the logit of the probability of colonization $(\gamma)$ is modeled as a linear function of connectivity alone. The model accounts for imperfect detection in the underlying occupancy data and allows parameter uncertainty to be propagated through to predictions of metapopulation viability.

The model was updated during this study by fitting it to a wider monitoring dataset, covering 190 sites monitored over 11 seasons (2001/2002 to 2011/2012; $n=2011$ surveys; Heard et al. 2015). This dataset includes all the previous surveys. We also added an effect of wetland type (pool along a stream or lentic wetland) on the probability of population persistence to account for higher rates of extinction along streams due to flooding. The model was fitted to the data using the Markov Chain Monte Carlo (MCMC) sampling following Royle and Kéry (2007).

To define the simulation model, estimates of the regression coefficients for the effects of the covariates on $\phi$ and $\gamma$ were inserted into the standard equation for changes in patch occupancy through time (MacKenzie et al. 2003):

$$
O_{i, \mathrm{t}+1}=o_{i, t} \times \phi_{i, t}+\left(1-o_{i, t}\right) \times \gamma_{i, t}
$$


where $O_{i, \mathrm{t}+1}$ is the probability of occupancy of patch $i$ at time $t+1, o_{i, t}$ is the occupancy status of patch $i$ at time $t$, and $\phi_{i, t}$ and $\gamma_{i, t}$ are the probabilities of persistence and colonization for patch $i$ at time $t$, respectively. Parametric uncertainty was included by repeating the simulations for 5000 sets of parameter estimates obtained from the MCMC algorithm (Heard et al. 2013). Simulations were run for 50 years in all scenarios.

\section{Scenarios of Urbanization and Conservation Alternatives}

We explored nine future scenarios representing proposed urbanization and alternate conservation management options for L. raniformis (Table 2). These scenarios were based on the CMP and consultation with Melbourne Water (the primary wetland managers). The simulation of each scenario involved a unique metapopulation configuration that reflects the details of the scenario (wetlands retained and created), and assumptions about how each scenario influences wetland quality.

\section{$\underline{\text { Initial conditions }}$}

Wetland characteristics (Table 1) were known for 48 sites, having been obtained during the monitoring described above or by Heard and McCarthy (2012). We used aerial imagery and waterway mapping to determine wetland type and effective area for the other 71 sites. Aquatic vegetation cover for these wetlands was unknown and set at the start of each simulation by making a random draw from a beta distribution with shape parameters estimated from the wider monitoring dataset. Surveys of 26 wetlands during the 2011/2012 active season were used to set their initial occupancy by L. raniformis. The remainder were given a $50 \%$ chance of being occupied at the start of each simulation, in line with the prevalence of L. raniformis among surveyed sites. The metapopulation was given 10 years to equilibrate, with urbanization and conservations actions set to begin in year 11 .

\section{$\underline{\text { Urbanization }}$}


Urbanization scenario U1 represents a baseline situation where the 51 wetlands designated as $\mathrm{C} 1$ habitat are retained and all others are destroyed (Table 2). This leaves 25 existing wetlands in the Precinct (Fig. 1). Aquatic vegetation cover at the retained wetlands was assumed to degrade due to catchment urbanization, which has previously been reported (Groffman et al. 2003; Akasaka et al. 2010). Given limited information on the magnitude and timing of vegetation loss, we trialed a down-weighting to the initial vegetation cover of up to $100 \%$, at increments of $25 \%$. This occurred linearly over five years after urbanization and values were held constant thereafter (i.e., stabilization to the new degraded state was assumed to occur within 5 years). Variation in the down-weighting factor had little impact on the costeffectiveness ranking (Appendix S2). Therefore, for simplicity, a down-weighting factor of $50 \%$ was applied to wetlands in all scenarios except those where aquatic vegetation maintenance was explicitly included (scenarios U1-3, A1b, A2b and A3b; Table 2).

Scenarios U2 and U3 examine the benefits to L. raniformis of creating SWM wetlands. In U2, all 30 SWM wetlands proposed for the Precinct are constructed, then left 'as is'. U3 is similar but includes resetting SWM wetlands at 20-year intervals for stormwater management functions. This entails complete drainage of wetlands, removal of built-up sediment and revegetation through direct planting (Melbourne Water 2013). We set wetlands to be absent in the resetting years, then reinstated effective area and aquatic vegetation cover to initial values the following year. The down-weighting factor was then re-applied. The location and size of SWM wetlands was dictated by the CMP, and they ranged from $190 \mathrm{~m}^{2}$ to $5200 \mathrm{~m}^{2}$ $\left(\right.$ mean $\left.=1940 \mathrm{~m}^{2}\right)$.

\section{$\underline{\text { Conservation alternatives }}$}

Our alternate conservation scenarios take $\mathrm{U} 1$ as their starting point (Table 2). We examined two broad strategies in the Precinct: creation of 22 L. raniformis-dedicated wetlands in the C1 zone and/or enhancement of the 25 existing $\mathrm{C} 1$ wetlands (Fig. 1). For the creation strategy, 
wetlands could be both created and maintained (scenario A1a) or created and left as is (scenario A1b, Table 2). For the enhancement strategy, enhancement could be 'basic' or 'moderate', and maintained or not. This yielded the following scenarios: basic enhancement and maintenance (A2a); basic enhancement without maintenance (A2b); moderate enhancement and maintenance (A3a); and, moderate enhancement without maintenance (A3b) (Table 2).

Dedicated wetlands in scenarios A1a and A1b included a mix of large $\left(3000-4000 \mathrm{~m}^{2}\right)$ and medium $\left(\sim 1000 \mathrm{~m}^{2}\right)$ wetlands that were spaced 150 - $200 \mathrm{~m}$ from each other and had an initial aquatic vegetation cover of $40 \%$ (we assumed plant establishment to be part of the construction process through direct planting). For the existing wetlands to be enhanced, aquatic vegetation cover was set at $40 \%$ for basic enhancement (as per the CMP) and at $60 \%$ for moderate enhancement (Heard et al. 2010; Heard et al. 2013). Where maintenance was included, we assumed that aquatic vegetation cover (Table 1) would remain the same across the simulation period (i.e. no down-weighting was applied). Where maintenance was not included, the down-weighting factor was applied to represent impacts of catchment urbanization (as above).

\section{$\underline{\text { Costs of candidate actions }}$}

The financial costs of each action were obtained from Melbourne Water through review of documentation on similar initiatives, plus workshops with managers and practitioners. Itemized costs were estimated on a per-square-meter or per-wetland basis (Table 2).

\section{Cost-effectiveness Analysis}

We adopted the number of wetlands occupied (nocc) in each year inside the Precinct as the metric of metapopulation viability (Heard et al. 2013), where nocc includes occupancy of both existing and new wetlands for each scenario. As we were interested in metapopulation 
viability in the long term, we measured the benefit of an action in terms of minimum number of wetlands occupied (minocc) over the last decade of the simulation period (41-50 years). Cost-effectiveness for each candidate action $a$ was calculated as the ratio of the benefit of that action $\left(B_{a}\right)$ to its financial cost $\left(C_{a}\right)$ in units of \$AU 1 million:

$$
R_{a}=B_{a} / C_{a}
$$

The benefit for action $a$ was the difference in minocc for this action and minocc for scenario U1 (no management actions beyond reservation of the $\mathrm{C} 1$ area). Hence:

$$
B_{a}=\operatorname{minocc}_{a}-\text { minocc }_{U 1} \text {. }
$$

$B$ and $R$ were calculated from simulations for each of the 5000 parameter sets, thereby producing posterior distributions for $B$ and $R$ for each management option. The mean and 95\% credible interval of $R$ for each scenario was calculated from the distributions.

\section{Results}

\section{Metapopulation Model}

Refitting the metapopulation model to the data showed that the probability of persistence of populations of $L$. raniformis was strongly positively related to wetland effective area and aquatic vegetation cover during the monitoring period, and was $\sim 20 \%$ higher in lentic wetlands than pools along streams (Table 3, Figure 2). Both the probability of persistence and colonization were positively related to connectivity, although the latter relationship was considerably stronger (Table 3, Fig. 2).

\section{Metapopulation Viability}

In the U1 baseline urbanization scenario, extinction of L. raniformis in the Precinct was possible - 15 years post development the mean nocc dropped by about three-quarters, while the lower bound of the $95 \%$ CI dropped to zero just two years later (Fig. 3). In contrast, when 
U1 was supplemented by the installation of 30 SWM wetlands (scenario U2), mean nocc was substantially higher, though there was large uncertainty around the predictions (Fig. 3). When SWM wetlands were subject to a resetting regime (scenario U3), nocc declined precipitously in reset years, but generally recovered rapidly (Fig. 3).

Conservation scenarios involving creation of L. raniformis-dedicated wetlands (A1a and A1b) performed better than any of the scenarios based on enhancing the $25 \mathrm{C} 1$ wetlands remaining in the Precinct (A2a, A2b, A3a and A3b). For scenario A1a (creation and maintenance of 22 L. raniformis-dedicated wetlands), mean nocc doubled by 10 years following implementation, and uncertainty continued to narrow as the lower bound of the 95\% CI rose with time. For scenario A2a (basic enhancement to $40 \%$ aquatic vegetation cover and maintenance of the 25 existing $\mathrm{C} 1$ wetlands) mean nocc fell immediately following urbanization and did not fully recover. When enhancement involved increasing and maintaining aquatic vegetation cover at $60 \%$ (scenario A3a), mean nocc eventually increased from around 16 to 20 .

Pairwise comparisons show that mean nocc was lower when maintenance was not included in the action set (Fig. 3). This was particularly evident for scenarios A2b and A3b, in which reductions in nocc of around 8 and 11 were predicted compared to when maintenance was included (A1a, A2a and A3a). For scenario A1b the drop in mean nocc was minimal; however, the 95\% CI widened by approximately 12 .

It is possible that L. raniformis would go extinct in the Precinct under enhancement actions alone, as shown by the lower limit of the $95 \%$ CIs for nocc in scenarios A2a, A2b, A3a and A3b (Fig. 3). Creation and maintenance of L. raniformis-dedicated wetlands (A1a) was the best performing conservation option with the highest increases in mean nocc and the narrowest $95 \% \mathrm{CI}$ bounds observed. 


\section{Cost-effectiveness Analysis}

Recalling that our measure of effectiveness is the change in minocc relative to the base urbanization scenario U1, the most cost-effective option was A1b (creation of dedicated wetlands for $L$. raniformis; mean $R=2.37$ ) followed by A1a (creation and maintenance of dedicated wetlands; mean $R=2.06$ ). These were around 10-12 times more cost-effective than the lowest ranking conservation option, A2b (Figure 4). Mean cost-effectiveness of $\mathrm{A} 3 \mathrm{a}$ ( $R$ of 1.25) was a moderate improvement on $\mathrm{A} 2 \mathrm{a}(R$ of 0.80$)$. However, when uncertainty in minocc is taken into account the rankings change slightly (Fig. 4). Scenario A1a had the narrowest range of uncertainty for $R$, whilst $\mathrm{A} 1 \mathrm{~b}$ had the widest and, according to the lower bound $(95 \% \mathrm{CI})$ for $R, \mathrm{~A} 1 \mathrm{a}$ was ranked first followed by A1b. These were the only actions that had near-zero probability of being futile (achieving no benefit for the cost of the action). Actions A2b and A3b both had negative $R$ values for the lower bound, indicating that these actions could potentially perform worse than taking no conservation actions (scenario U1).

\section{Discussion}

Management agencies and policy-makers require tools to identify the most cost-effective options for reducing or minimizing species extinction risks. Here, we have demonstrated an approach to incorporating parametric and demographic uncertainty in population projections to evaluate the cost-effectiveness and robustness of conservation actions. Our approach utilizes a Bayesian metapopulation model, allowing model uncertainty to be carried through to, and represented in, the prediction of benefit and cost-effectiveness of multiple conservation options.

The bulk of conservation planning literature focuses on reserve creation, though this action alone does not necessarily ensure the persistence of biodiversity in the long-term (Liu et al. 2001; Leisher et al. 2013). In our study, simulation of metapopulation viability under a purely 
reserve-based scenario (protecting existing core habitat, but not compensating habitat losses) suggests that our focal species - the endangered frog Litoria raniformis - could go extinct in the Precinct soon after development. This highlights the value of examining a suite of habitat management options rather than just binary reserve-or-not conservation actions (SebastiánGonzález et al. 2011; Pouzols et al. 2012).

In our study, habitat creation actions performed better than enhancement actions. However, in both cases, metapopulation persistence was highly sensitive to the extent and maintenance of these actions, and ranking changed depending on the consideration of uncertainty. The key insight from the CEA incorporating uncertainty was that while scenario A1b (creation but not maintenance of wetlands dedicated to L. raniformis) was ranked the most cost-effective option based on the mean minimum occupancy (minocc), scenario A1a (creation and maintenance of dedicated wetlands) was the most cost-effective when one focuses on the lower 95\% CI of minocc (Fig. 4). Hence, the CEA reveals that guarding against worst-case uncertainty would lead to pursuit of the nominally more expensive, but more reliable A1a.

Wetland creation actions were most effective because they involve controlling two key drivers of metapopulation persistence for L. raniformis: the effective area of wetlands in the network and their and connectivity (through the number and proximity of wetlands). In contrast, enhancement only influences aquatic vegetation cover. Nevertheless, the extent of enhancement of aquatic vegetation was important for long-term metapopulation viability. When only basic revegetation (40\% cover) was adopted (A2a or A2b), mean nocc never recovered to original levels in the 40 years following urbanization. However, when revegetation increases to $60 \%$ (A3a or $\mathrm{A} 3 \mathrm{~b}$ ), mean nocc was $~ 50 \%$ higher than under basic revegetation (Fig. 3). This reflects the sigmoidal relationship between population persistence and aquatic vegetation cover, where mid-range changes in cover give the greatest proportional increase in the probability of persistence (Fig. 2b). This is an important insight, 
because it may be more cost-effective to revegetate more extensively, particularly if the cost of extra plants was small relative to other fixed costs, such as site investigations and set-up materials. This was true in our case, where the mean cost-effectiveness ratio $(R)$ of scenario A3a ( $60 \%$ cover) was markedly higher than that of A2a ( $40 \%$ cover).

In cost-effective prioritization, few studies account for uncertainty in the effect of actions (Bryan 2010) or offer guidance on how to identify cost-effective options that are robust to uncertainty (Pouzols et al. 2012). Using a Bayesian metapopulation model to incorporate uncertainty in estimates of cost-effectiveness elucidated important risks that would have been missed if we had only used point estimates (e.g. the mean) for metapopulation viability and the cost-effectiveness ratio. In our case study, accounting for uncertainty demonstrated that scenarios A1a and A1b (creation of wetlands dedicated to L. raniformis) were the only actions with near-zero probability of extinction over a 50-year timeframe after accounting for parametric and demographic uncertainty. Interestingly, while the mean (or 'expected') costeffectiveness of $\mathrm{A} 1 \mathrm{~b}$ is higher than the mean cost-effectiveness for A1a, the lower bound of A1b is lower relative to A1a, indicating a less satisfactory 'worst-case' outcome (as above). This highlights the need for decision makers to be clear about risk tolerance, because the choice between these two management options is sensitive to it. For example, if the hypothetical horizontal dashed line in Fig. 4 represented the minimum satisfactory performance specified by a decision maker, then the winning option is A1a because all other options have the possibility of falling below this line. This form of robustness analysis cannot be achieved without explicitly modeling uncertainty as we have done here. The wide bounds around all other options indicate relatively low immunity to the patently unsatisfactory outcome of local extinction.

Our assumptions about the impact of urbanization on aquatic vegetation cover in the study area had to be simplified due to the absence of data on this specific impact in our region. 
However, the existence of an impact is supported by considerable evidence showing declines in aquatic biodiversity with catchment urbanization (e.g. Booth \& Jackson 1997; Walsh et al. 2005; Akasaka et al. 2010; Canessa \& Parris 2013). The strong influence of vegetation cover on our benefit measure nocc and the sensitivity of persistence to small changes in revegetation indicates that uncertainty about the magnitude of urbanization impacts on vegetation is an important uncertainty that should be resolved as a matter of priority. It also suggests a precautionary approach to ongoing, rather than 'one-off' restorations actions, would be prudent until the local vegetation dynamics are better understood.

Large benefits in metapopulation viability were found for simulations involving the installation of SWM wetlands. However, there are at least three reasons why this should be interpreted with caution. First, the posterior bounds for scenario U2 and U3 predictions were wide (Fig. 3). Second, SWM wetlands accumulate nutrients and pollutants from stormwater runoff over time and these chemicals are known to affect larval survival and development of some amphibians (Snodgrass et al. 2008; Brand et al. 2010). If pollutant build-up in SWM wetlands affects $L$. raniformis similarly, the contribution of these wetlands to metapopulation persistence may be lower than our modeling suggests. Third, some types of SWM design are known to degrade receiving waters (Walsh et al. 2005; Walsh et al. 2012) and we are uncertain exactly how the SWM design in the Precinct and local catchments will eventuate and alter conditions within existing habitat. Monitoring of stormwater impacts and mitigation actions is required for L. raniformis and other wetland biota to fill this knowledge gap.

Given the number of threatened species and the limited resources to conserve them, costeffective prioritization should be core business for modern conservation practitioners. However, CEA that ignores uncertainty may lead to the adoption of fragile management decisions and strategies that are not robust to known uncertainties. We encourage efforts to 
deal with uncertainty in conservation management prioritization using systematic approaches such as the one we present here.

\section{Acknowledgments}

This work was supported by the National Environment Research Program Environmental Decisions Hub, Australian Research Council (ARC Centre of Excellence for Environmental Decisions and LP0990161), Australian Research Centre for Urban Ecology, Victorian Department of Environment and Primary Industries, Growling Grass Frog Trust Fund, Museums Victoria, Melbourne Water and Parks Victoria. We thank K. Morris, M. Burgman and T. Hollings for their helpful comments on earlier versions of the draft. D. DeAngelis, A. Hamer, C. Keely, P. Robertson and D. Stokeld are thanked for their contribution to surveys, along with numerous other colleagues and volunteers. We also thank Melbourne Water staff who participated in workshops and discussions about the case study, especially A. Danger and D. Carew. LR is funded by a Melbourne Research Scholarship and Melbourne Water's Research Program. GWH was supported by a Victorian Postdoctoral Research Fellowship. YEC is supported by an ARC Linkage Project (LP110100304). BAW is supported by an ARC Future Fellowship (FT100100819).

\section{Supporting Information}

Summaries of the CMP and SRS (Appendix S1) and the sensitivity analysis on the assumptions of urbanization effects on aquatic vegetation cover (Appendix S2) are also available online. The authors are solely responsible for the content and functionality of these materials. Queries (other than absence of the material) should be directed to the corresponding author. 


\section{Literature Cited}

Addison, P. F. E., L. Rumpff, S. S. Bau, J. M. Carey, Y. E. Chee, F. C. Jarrad, M. F. McBride, and M. A. Burgman. 2013. Practical solutions for making models indispensable in conservation decision-making. Diversity and Distributions 19:490502.

Akasaka, M., N. Takamura, H. Mitsuhashi, and Y. Kadono. 2010. Effects of land use on aquatic macrophyte diversity and water quality of ponds. Freshwater Biology 55:909922.

Akçakaya, R. H., M. A. McCarthy, and J. L. Pearce. 1995. Linking landscape data with population viability analysis: Management options for the helmeted honeyeater Lichenostomus melanops cassidix. Biological Conservation 73:169-176.

Booth, D. B., and C. R. Jackson. 1997. Urbanization of aquatic systems: degradation thresholds, stormwater detection, and the limits of mitigation. JAWRA Journal of the American Water Resources Association 33:1077-1090.

Brand, A., J. Snodgrass, M. Gallagher, R. Casey, and R. Van Meter. 2010. Lethal and Sublethal Effects of Embryonic and Larval Exposure of Hyla versicolor to Stormwater Pond Sediments. Archives of Environmental Contamination and Toxicology 58:325-331.

Bryan, B. A. 2010. Development and application of a model for robust, cost-effective investment in natural capital and ecosystem services. Biological Conservation 143:1737-1750.

Burgman, M. A., S. Ferson, and H. R. Akcakaya 1993. Risk assessment in conservation biology. Chapman \& Hall, London.

Cabeza, M., and A. Moilanen. 2001. Design of reserve networks and the persistence of biodiversity. Trends in Ecology \& Evolution 16:242-248. 
Canessa, S., and K. M. Parris. 2013. Multi-Scale, Direct and Indirect Effects of the Urban Stream Syndrome on Amphibian Communities in Streams. PLoS ONE 8:e70262.

DEPI. 2013. Sub-regional species strategy for the growling grass frog. Victorian Department of Environment and Primary Industries, Melbourne.

Duca, C., H. Yokomizo, M. A. Marini, and H. P. Possingham. 2009. Cost-efficient conservation for the white-banded tanager (Neothraupis fasciata) in the Cerrado, central Brazil. Biological Conservation 142:563-574.

Ecology Australia. 2012. Growling Grass Frog Conservation Management Plan: Lockerbie Precinct - Draft, Ecology Australia, Melbourne.

Ferraro, P. J. 2003. Assigning priority to environmental policy interventions in a heterogeneous world. Journal of Policy Analysis and Management 22:27-43.

Fuentes, M., J. Blackwood, B. Jones, M. Kim, B. Leis, C. J. Limpus, H. Marsh, J. Mitchell, F. M. Pouzols, R. L. Pressey, and P. Visconti. 2015. A decision framework for prioritizing multiple management actions for threatened marine megafauna. Ecological Applications 25:200-214.

GAA. 2012. Lockerbie Precinct Structure Plan, Growth Areas Authority, Melbourne Gilioli, G., A. Bodini, J. Baumgartner, P. Weidmann, and J. Hartmann. 2008. A novel approach based on information theory to rank conservation strategies: an application to amphibian metapopulations. Animal Conservation 11:453-462.

Groffman, P. M., D. J. Bain, L. E. Band, K. T. Belt, G. S. Brush, J. M. Grove, R. V. Pouyat, I. C. Yesilonis, and W. C. Zipperer. 2003. Down by the riverside: urban riparian ecology. Frontiers in Ecology and the Environment 1:315-321.

Guisan, A., R. Tingley, J. B. Baumgartner, I. Naujokaitis-Lewis, P. R. Sutcliffe, A. I. T. Tulloch, T. J. Regan, L. Brotons, E. McDonald-Madden, C. Mantyka-Pringle, T. G. Martin, J. R. Rhodes, R. Maggini, S. A. Setterfield, J. Elith, M. W. Schwartz, B. A. 
Wintle, O. Broennimann, M. Austin, S. Ferrier, M. R. Kearney, H. P. Possingham, and Y. M. Buckley. 2013. Predicting species distributions for conservation decisions. Ecology Letters 16:1424-1435.

Hamer, A., P. Smith, and M. McDonnell. 2012. The importance of habitat design and aquatic connectivity in amphibian use of urban stormwater retention ponds. Urban Ecosystems 15:451-471.

Heard, G. W., and M. A. McCarthy. 2012. Metapopulation viability of the Growling Grass Frog in Melbourne's urban growth areas. Report to the Victorian Department of Sustainability and Environment, Melbourne.

Heard, G. W., M. A. McCarthy, M. P. Scroggie, J. B. Baumgartner, and K. M. Parris. 2013. A Bayesian model of metapopulation viability, with application to an endangered amphibian. Diversity and Distributions 19:555-566.

Heard, G. W., M. P. Scroggie, and N. Clemann. 2010. Guidelines for managing the endangered Growling Grass Frog in urbanising landscapes. . Technical Report S-208. Department of Environment and Primary Industries Heidelberg, Victoria.

Heard, G. W., M. P. Scroggie, and B. S. Malone. 2012a. Classical metapopulation theory as a useful paradigm for the conservation of an endangered amphibian. Biological Conservation 148:156-166.

Heard, G. W., M. P. Scroggie, and B. S. Malone. 2012b. The life history and decline of the threatened Australian frog, Litoria raniformis. Austral Ecology 37:276-284.

Heard, G. W., C. D. Thomas, J. A. Hodgson, M. P. Scroggie, D. S. L. Ramsey, and N. Clemann. 2015. Refugia and connectivity sustain amphibian metapopulations afflicted by disease. Ecology Letters. 
Joseph, L. N., R. F. Maloney, and H. P. Possingham. 2009. Optimal allocation of resources among threatened species: a project prioritization protocol. Conservation Biology 23:328-338.

Kuemmerle, T., K. Perzanowski, H. R. Akcakaya, F. Beaudry, T. R. Van Deelen, I. Parnikoza, P. Khoyetskyy, D. M. Waller, and V. C. Radeloff. 2011. Costeffectiveness of strategies to establish a European bison metapopulation in the Carpathians. Journal of Applied Ecology 48:317-329.

Leisher, C., J. Touval, S. M. Hess, T. M. Boucher, and L. Reymondin. 2013. Land and Forest Degradation inside Protected Areas in Latin America. Diversity 5:779-795.

Liu, J. G., M. Linderman, Z. Y. Ouyang, L. An, J. Yang, and H. M. Zhang. 2001. Ecological degradation in protected areas: The case of Wolong Nature Reserve for giant pandas. Science 292:98-101.

MacKenzie, D. I., J. D. Nichols, J. E. Hines, M. G. Knutson, and A. B. Franklin. 2003. Estimating site occupancy, colonization, and local extinction when a species is detected imperfectly. Ecology 84:2200-2207.

Melbourne Water. 2013. Stormwater Strategy: A Melbourne Water strategy for managing urban and rural runoff Melbourne Water, Melbourne.

Naidoo, R., A. Balmford, P. J. Ferraro, S. Polasky, T. H. Ricketts, and M. Rouget. 2006. Integrating economic costs into conservation planning. Trends in Ecology \& Evolution 21:681-687.

Newbold, S. C., and J. Siikamäki. 2009. Prioritizing conservation activities using reserve site selection methods and population viability analysis. Ecological Applications 19:17741790. 
Pouzols, F. M., M. A. Burgman, and A. Moilanen. 2012. Methods for allocation of habitat management, maintenance, restoration and offsetting, when conservation actions have uncertain consequences. Biological Conservation 153:41-50.

Royle, J. A., and M. Kéry. 2007. A Bayesian state-space formulation of dynamic occupancy models. Ecology 88:1813-1823.

Santika, T., C. A. McAlpine, D. Lunney, K. A. Wilson, and J. R. Rhodes. 2015. Assessing spatio-temporal priorities for species' recovery in broad-scale dynamic landscapes. Journal of Applied Ecology.

Sebastián-González, E., J. A. Sánchez-Zapata, F. Botella, J. Figuerola, F. Hiraldo, and B. A. Wintle. 2011. Linking cost efficiency evaluation with population viability analysis to prioritize wetland bird conservation actions. Biological Conservation 144:2354-2361.

Smith, R., and W. Sutherland 2014. Amphibian Conservation: Global evidence for the effects of interventions. Pelagic Publishing, Exeter.

Snodgrass, J. W., R. E. Casey, D. Joseph, and J. A. Simon. 2008. Microcosm investigations of stormwater pond sediment toxicity to embryonic and larval amphibians: Variation in sensitivity among species. Environmental Pollution 154:291-297.

Southwell, D. M., A. M. Lechner, T. Coates, and B. A. Wintle. 2008. The sensitivity of population viability analysis to uncertainty about habitat requirements: implications for the management of the endangered southern brown bandicoot. Conservation Biology 22:1045-1054.

Victorian Stormwater Committee. 1999. Urban stormwater : best practice environmental management guidelines, CSIRO, Melbourne.

Visconti, P., R. L. Pressey, D. B. Segan, and B. A. Wintle. 2010. Conservation planning with dynamic threats: The role of spatial design and priority setting for species' persistence. Biological Conservation. 
Walsh, C. J., T. D. Fletcher, and M. J. Burns. 2012. Urban Stormwater Runoff: A New Class of Environmental Flow Problem. Plos One 7.

Walsh, C. J., T. D. Fletcher, and A. R. Ladson. 2005. Stream restoration in urban catchments through redesigning stormwater systems: looking to the catchment to save the stream. Journal of the North American Benthological Society 24:690-705.

Watts, M. E., I. R. Ball, R. S. Stewart, C. J. Klein, K. Wilson, C. Steinback, R. Lourival, L. Kircher, and H. P. Possingham. 2009. Marxan with Zones: Software for optimal conservation based land- and sea-use zoning. Environmental Modelling \& Software 24:1513-1521.

Wilson, K. A., M. F. McBride, M. Bode, and H. P. Possingham. 2006. Prioritizing global conservation efforts. Nature 440:337-340.

Wilson, K. A., E. C. Underwood, S. A. Morrison, K. R. Klausmeyer, W. W. Murdoch, B. Reyers, G. Wardell-Johnson, P. A. Marquet, P. W. Rundel, M. F. McBride, R. L. Pressey, M. Bode, J. M. Hoekstra, S. Andelman, M. Looker, C. Rondinini, P. Kareiva, M. R. Shaw, and H. P. Possingham. 2007. Conserving biodiversity efficiently: what to do, where, and when. PLoS Biol 5:e223.

Wintle, B. A., S. A. Bekessy, D. A. Keith, B. W. van Wilgen, M. Cabeza, B. Schroder, S. B. Carvalho, A. Falcucci, L. Maiorano, T. J. Regan, C. Rondinini, L. Boitani, and H. P. Possingham. 2011. Ecological-economic optimization of biodiversity conservation under climate change. Nature Climate Change 1:355-359.

Wintle, B. A., S. A. Bekessy, L. A. Venier, J. L. Pearce, and R. A. Chisholm. 2005. Utility of dynamic-landscape metapopulation models for sustainable forest management. Conservation Biology 19:1930-1943. 
Table 1: Definitions of variables used to model the probabilities of population persistence $(\phi)$ and colonization $(\gamma)$ for Litoria raniformis in the study area (adapted from Heard et al. 2013).

\begin{tabular}{|c|c|}
\hline Variable & Definition \\
\hline Effective area $\left(A_{\text {eff }}\right)$ & $\begin{array}{l}A_{\text {eff }}=(\log (A) \times H) / H_{\max } \\
A \text { is wetland surface area }\left(\mathrm{m}^{2}\right), H \text { is hydroperiod, measured } \\
\text { on an ordinal scale between } 1 \text { (temporarily fills only during } \\
\text { high rainfall) and } 4 \text { (permanently inundated), and } H_{\max } \text { is } \\
\text { the maximum hydroperiod score. }\end{array}$ \\
\hline $\begin{array}{l}\text { Aquatic vegetation } \\
\text { cover }(V)\end{array}$ & $\begin{array}{l}\text { The mean cover }(\%) \text { of the three dominant growth forms of } \\
\text { aquatic macrophytes: emergent, submergent and floating }\end{array}$ \\
\hline $\begin{array}{l}\text { Wetland type (pool } \\
\text { along a stream or lentic } \\
\text { wetland) }\end{array}$ & $\begin{array}{l}\text { Binary variable taking the value of } 1 \text { for lotic pools and } 0 \\
\text { for lentic wetlands. }\end{array}$ \\
\hline Connectivity $\left(S_{i, t}\right)$ & $\begin{array}{l}S_{i, t}=\sum w_{i, j} \times o_{j, t} \\
w_{i, j} \text { is a weighting function, } o_{j, t} \text { is the occupancy status of } \\
\text { each neighbor } j \text { in year } t \text {. Only wetlands within } 1 \mathrm{~km} \text { of the } \\
\text { focal wetland are considered neighbours. } w_{i, j} \text { defines a } \\
\text { negative power relationship between the probability of } \\
\text { dispersal from wetland } i \text { to } j \text { and the Euclidean distance } \\
\text { between their centres (see Heard et al. 2013). } S_{i, t} \text { was } \\
\text { log }(x+1) \text { transformed for the analyses. }\end{array}$ \\
\hline
\end{tabular}


Table 2: Details and key differences of the nine scenarios evaluated, with scenario U1 forming the baseline for all other scenarios. Values used for all new wetlands (L. raniformis-dedicated and SWM) were based on the Conservation Management Plan (Ecology Australia 2012), recent surveys and data provided by Melbourne Water (the primary management agency for SWM wetlands in the Precinct).

\begin{tabular}{|c|c|c|c|c|}
\hline \multicolumn{2}{|c|}{ Scenario/Action } & Action Description & Key changes to model variables & $\begin{array}{l}\text { Cost of } \\
\text { action } \\
\text { (\$AUD } \\
1 \text { million) }\end{array}$ \\
\hline U1 & Remove habitat \& develop & $\begin{array}{l}\text { Remove } 68 \text { sites in non-C1 habitat (area } \\
\text { designated for development). } \\
\text { Reserve } 51 \text { sites in } \mathrm{C} 1 \text { habitat; } 25 \text { of which } \\
\text { are in the Precinct }\end{array}$ & $\begin{array}{l}\text { Down-weighting factor }(50 \%) \\
\text { applied to } V \text { in remaining wetlands }\end{array}$ & 0 \\
\hline $\mathrm{U} 2$ & $\begin{array}{l}\text { Remove habitat, develop, construct } \\
\text { all proposed SWM wetlands }\end{array}$ & $\begin{array}{l}\text { U1 plus construct all } 30 \text { SWM wetlands in } \\
\text { the Precinct: } \\
\text { Construct SWM wetlands } \\
\text { Interpretive signage, design cost, contract } \\
\text { cost } \\
\text { Maintenance for } 2 \text { years }\end{array}$ & $\begin{array}{l}V_{S W M}=22 \% \\
\text { Down-weighting applied to new } \\
\text { wetlands } \\
H_{S W M}=4 \text { (permanently inundated) }\end{array}$ & N/A \\
\hline $\mathrm{U} 3$ & Remove habitat, develop, construct \& & $\begin{array}{l}\text { As U2 plus reset SWM wetlands every } 20 \\
\text { years for stormwater functions: }\end{array}$ & As for $\mathrm{U} 2$ & N/A \\
\hline
\end{tabular}




\begin{tabular}{|c|c|c|c|c|}
\hline & maintain all proposed SWM wetlands & Drain, remove sediment, revegetate & $\begin{array}{l}\text { All variables set to zero for resetting } \\
\text { year. Values restored following year }\end{array}$ & \\
\hline Ala & $\begin{array}{l}\text { Create \& maintain all wetlands } \\
\text { dedicated to L. raniformis proposed } \\
\text { in CMP. }\end{array}$ & $\begin{array}{l}\text { U1 plus create \& maintain all } 22 \text { dedicated } \\
\text { wetlands proposed for the Precinct C1 area: } \\
\text { Establish } 40 \% \text { aquatic vegetation cover } \\
\text { Vegetate a } 10 \text { m buffer around wetland } \\
\text { Install rocks \& logs } \\
\text { Signage, design \& contract cost } \\
\text { Construction amenity set up } \\
\text { Ongoing maintenance }\end{array}$ & $\begin{array}{l}V_{c}=40 \% \\
\text { No down-weighting applied to } V_{c} \\
H_{c}=4 \text { (permanently inundated) }\end{array}$ & 16 \\
\hline A1b & $\begin{array}{l}\text { Create all dedicated wetlands } \\
\text { proposed in CMP. }\end{array}$ & $\begin{array}{l}\text { Same as A1a but without ongoing } \\
\text { maintenance }\end{array}$ & $\begin{array}{l}\text { As in A1a but down-weighting } \\
\text { applied to } V_{c}\end{array}$ & 13 \\
\hline
\end{tabular}




\begin{tabular}{|c|c|c|c|c|}
\hline & & Ongoing maintenance & & \\
\hline $\mathrm{A} 2 \mathrm{~b}$ & $\begin{array}{l}\text { Basic enhancement of all existing } \\
\text { wetlands in } \mathrm{C} 1 \text { area of the Precinct. }\end{array}$ & Same as A2a but without maintenance & $\begin{array}{l}\text { As A2a but down-weighting applied } \\
\text { to } V_{e}\end{array}$ & 9 \\
\hline A3a & $\begin{array}{l}\text { Moderate enhancement \& } \\
\text { maintenance of all existing wetlands } \\
\text { in } \mathrm{C} 1 \text { area of the Precinct. }\end{array}$ & $\begin{array}{l}\text { U1 plus enhance \& maintain the remaining } \\
25 \text { existing wetlands in the Precinct : } \\
\text { Revegetate to } 60 \% \text { aquatic vegetation } \\
\text { cover } \\
\text { Weeding and planting (to } 10 \mathrm{~m} \text { around } \\
\text { wetland) } \\
\text { Install rocks \& logs } \\
\text { Signage, design \& contract cost } \\
\text { Ongoing maintenance }\end{array}$ & $\begin{array}{l}V_{e}=60 \% \\
\text { No down-weighting applied to } V_{e}\end{array}$ & 13 \\
\hline
\end{tabular}

${ }^{a} \mathrm{C} 1$ = Category 1 habitat

${ }^{b} V=$ aquatic vegetation cover of wetlands (mean cover of emergent, submergent and floating macrophytes)

${ }^{c} \mathrm{SWM}=$ wetlands designed for stormwater management (water quality treatment and flow retention)

${ }^{d} V_{S W M}=$ aquatic vegetation cover of SWM wetlands (mean cover of emergent, submergent and floating aquatic macrogphytes)

${ }^{e} H_{S W M}=$ hydroperiod of SWM wetlands

${ }^{f} \mathrm{CMP}=$ Conservation Management Plan area 
${ }^{g} V_{c}=$ aquatic vegetation cover of created wetlands

${ }^{h} H_{c}=$ hydroperiod of created wetlands

${ }^{i} V_{e}=$ aquatic vegetation cover of enhanced wetlands. 
Table 3. Summary statistics for the posterior distributions of the regression coefficients for the effects of effective wetland area $\left(A_{\text {eff }}\right)$, aquatic vegetation cover $(V)$, site type and connectivity $(S, \log$ transformed) on the probabilities of population persistence and colonization for Litoria raniformis. The summaries are based on the 5,000 samples from the posterior $^{a}$, as used for the simulations of metapopulation viability.

\begin{tabular}{|l|l|l|l|l|l|}
\hline Probability of & Parameter & Effect of & mean & Lower & Upper \\
& & & & 95\% CI & 95\% CI \\
\hline Colonization & $\alpha_{\gamma}$ & - & -3.177 & -3.746 & -2.615 \\
\hline Colonization & $\beta_{\gamma 1}$ & $S$ & 6.774 & 4.127 & 9.816 \\
\hline Persistence & $\alpha_{\phi}$ & - & & & \\
\hline Persistence & $\beta_{\phi 1}$ & $A_{\text {eff }}$ & 0.813 & 0.518 & 1.181 \\
\hline Persistence & $\beta_{\phi 2}$ & V & 0.098 & 0.050 & 0.162 \\
\hline Persistence & $\beta_{\phi 3}$ & Site type & -1.244 & -2.475 & -0.249 \\
\hline Persistence & $\beta_{\phi 4}$ & S & 3.129 & 1.208 & 5.514 \\
\hline
\end{tabular}

${ }^{a}$ Extracted following convergence of two MCMC chains with over-dispersed starting values. Convergence was assessed visually, and parameter values extracted after a burn-in of 30,000 MCMC samples. 
Figure 1: Study site, showing the Lockerbie Precinct boundary, local catchment areas draining toward the metapopulation, and $1 \mathrm{~km}$ buffer around the core metapopulation. Red shading shows the core wetlands previously identified (Heard \& McCarthy 2012; Heard et al. 2013) and olive green shading denotes the Category 1 (C1) habitat zone taken from DEPI (2013) . The focal metapopulation includes all 119 wetlands within the buffer, the Precinct and/or the local catchment area. The conservation management plan area relates only to the C1 zone within the Precinct.

Figure 2: Relationship between the probability of persistence $(\phi)$ of Litoria raniformis populations and (a) effective wetland area $\left(A_{\text {eff }}\right),(\mathrm{b})$ aquatic vegetation cover $(V)$, (c) wetland type and (d) connectivity ( $S, \log$ transformed), and the relationship between the probability of colonization $(\gamma)$ of vacant wetlands and connectivity $(S$, log transformed). The thick black lines represent the posterior mean relationship, and thin black lines the $95 \%$ credible interval. Relationships are shown with all other variables held at their mean values.

Figure 3: Variation in wetland occupancy (nocc) in the Precinct with time since urbanization for nine urbanization and conservation scenarios. The black line denotes the mean estimate and the dark grey lines the $95 \%$ credible interval. Scenarios are: U1) urbanization only; U2) urbanization plus installation of all 30 stormwater management (SWM) wetlands; U3) U2 with resetting of SWM wetlands; A1a) U1 plus creation of 22 L. raniformis-dedicated wetlands; A1b) A1a without maintenance of the dedicated wetlands; A2a) U1 plus basic enhancement to $40 \%$ aquatic vegetation cover of 25 existing $\mathrm{C} 1$ wetlands in the Precinct; A2b) A2a without maintenance of enhancements; A3a) U1 plus moderate enhancement to $60 \%$ aquatic vegetation cover of 25 existing wetlands in the Precinct, and; A3b) A3a without maintenance of enhancements. 
Figure 4: Mean (black dot) and 95\% credible interval (grey line) for the cost-benefit ratio $(R)$ of six alternative conservation actions: A1a) U1 plus creation of 22 L. raniformis-dedicated wetlands; A1b) A1a without maintenance of the dedicated wetlands; A2a) U1 plus basic enhancement to $40 \%$ aquatic vegetation cover of 25 existing C1 wetlands in the Precinct; A2b) A2a without maintenance of enhancements; A3a) U1 plus moderate enhancement to $60 \%$ aquatic vegetation cover of 25 existing wetlands in the Precinct, and; A3b) A3a without maintenance of enhancements. The dashed line indicates a hypothetical minimum performance threshold to help elucidate the difference between expected outcome and robustness to uncertainty. 